\title{
VARIACIÓN EN GERMINACIÓN SIMBIÓTICA ENTRE SEMILLAS DE TOLUMNIA VARIEGATA Y ENTRE HONGOS MICORRÍZICOS
}

\author{
J. TUPAC OTERO ${ }^{1}$, PAUL BAYMAN ${ }^{2} \&$ JAMES D. ACKERMAN $^{2}$ \\ Departamento de Biología, Universidad de Puerto Rico-Río Piedras \\ PO Box 23360, San Juan, PR 00931-3360, U.S.A. \\ ${ }^{1}$ Dirección actual: CSIRO Plant Industry, Center for Plant Biodiversity Research, Australian National Herbarium, \\ GPO Box 1600, Canberra ACT 2601, Australia \\ ${ }^{2}$ Author for correspondence: pbayman@upracd.upr.clu.edu
}

Desde hace cien años se sabe que las semillas de las orquídeas necesitan hongos micorrízicos para germinar. Todavía no se sabe si las orquídeas pueden evolucionar para aprovechar mejor los hongos micorrízicos, y si las micorrizas han contribuido en la diversidad de las orquídeas.

En un estudio previo, aislamos hongos micorrízicos de plantas adultas de varias especies de orquídeas en Puerto Rico (Otero et al. 2002). Los hongos fueron identificados por medio de secuenciación de la región ITS de los genes ribosomales nucleares. En el análisis filogenético de los hongos resultaron cuatro clados principales. Los cuatro se anidan dentro de Ceratobasidium, un género ya conocido de hongos micorrzticos de orquídeas. Todos los hongos aislados de la orquídea Ionopsis utricularioides pertenecieron a un sólo clado de Ceratobasidium. En cambio, Tolumnia variegata parecía más generalista en cuanto a sus relaciones con hongos micorrízicos: sus cepas pertenecen a los cuatro clados principales. Dichos resultados sugieren que hay variación entre especies de orquídeas en el grado de especificidad para hongos micorrízicos.

Este estudio se basó en dos preguntas: ¿Hay variación entre plantas de una población de orquídeas en su capacidad para la germinación simbiótica? ¿Le da igual a una semilla de orquídea asociarse con diferentes hongos, o hay diferencias funcionales entre hongos? Para contestar estas preguntas se estudió la orquídea epífita $T$. variegata, por tener diversidad de hongos micorrízicos. Hongos del género Ceratobasidium fueron aislados de raíces de $T$. varie gata en la Reserva Laguna Tortuguero, Puerto Rico. Frutos de T. variegata fueron recogidos de la misma población. Las semillas fueron germinadas en medios de cultivo con la presencia de diferentes cepas del hongo. Hubo diferencias significativas entre 10 frutos en germinación y crecimiento de semillas con los mismos hongos.

Los nueve hongos difieren significativamente en su capacidad para estimular el crecimiento de semillas. Además, se observan diferencias entre orquídeas, incluso dentro de una población, respecto a la capacidad para aprovechar los hongos micorrízicos.

Estos resultados sugieren que existe el potencial para la evolución de especificidad en la interacción entre las orquídeas y sus hongos micorrízicos, y que dichas relaciones pueden causar especiación de orquídeas por selección natural.

\section{LiteratURA CiTADA}

Otero J.T., J.D. Ackerman \& P. Bayman. 2002. Diversity and host specificity of endophytic Rhizoctonia-like fungi from tropical orchids. Amer. J. Bot. 89: 1852-1858.

J. Tupac Otero es Investigador Postdoctoral en CSIRO Plant Industry, Canberra, Australia. Es ecólogo con Ph.D., que estudia las interacciones entre orquídeas, hongos y abejas.

Paul Bayman Gupta es Catedrático Asociado de Biología en la Universidad de Puerto Rico, Río Piedras, con el grado de Ph.D. Es micólogo y estudia las interacciones planta-hongo y micotoxinas.

James D. Ackerman es Catedrático de Biología en la Universidad de Puerto Rico, Río Piedras, con el grado de Ph.D. Es orquideólogo y estudia polinización y sistemática. 